\title{
Two-Phase Cooling Method Using R134a Refrigerant to Cool Power Electronic Devices
}

\author{
Jeremy B. Campbell ${ }^{1}$ \\ jcampb13@utk.edu \\ Leon M. Tolbert ${ }^{1,2}$
tolbert@utk.edu \\ ${ }^{1}$ Department of Electrical and Computer Engineering \\ The University of Tennessee \\ Knoxville, TN 37996-2100
}

\author{
Curt W. Ayers ${ }^{2}$ \\ ayerscw@ornl.gov \\ Burak Ozpineci² \\ burak@ieee.org
${ }^{2}$ National Transportation Research Center
Oak Ridge National Laboratory
Knoxville, TN 37932

\begin{abstract}
This paper presents a two-phase cooling method using R134a refrigerant to dissipate the heat energy (loss) generated by power electronics (PE) such as those associated with rectifiers, converters, and inverters for a specific application in hybrid-electric vehicles (HEVs). The cooling method involves submerging $P E$ devices in an R134a bath, which limits the junction temperature of $P E$ devices while conserving weight and volume of the heat sink without sacrificing equipment reliability.

First, experimental tests that included an extended soak for more than 300 days were performed on a submerged IGBT and gate-controller card to study dielectric characteristics, deterioration effects, and heat flux capability of R134a. Results from these tests illustrate that R134a has high dielectric characteristics, no deterioration on electrical components, and a heat flux of $114 \mathrm{~W} / \mathrm{cm}^{2}$ for the experimental configuration.

Second, experimental tests that included simultaneous operation with a mock automotive air-conditioner (A/C) system were performed on the same IGBT and gate controller card. Data extrapolation from these tests determined that a typical automotive $\mathrm{A} / \mathrm{C}$ system has more than sufficient cooling capacity to cool a typical $30 \mathrm{~kW}$ traction inverter.

Last, a discussion and simulation of active cooling of the IGBT junction layer with R134a refrigerant is given. This technique will drastically increase the forward current ratings and reliability of the PE device.
\end{abstract}

\section{INTRODUCTION}

As the cost of oil increases and oil stockpiles diminish, consumers recognize the importance of alternatively fueled vehicles. Presently, the most promising of these vehicles are hybrid-electric vehicles (HEVs) because of the latest technology in power electronics (PE) that maximizes energy usability and efficiency. PE provide the interface between the energy sources such as batteries and the traction drive motor.

The typical location for these PE packages is in the engine compartment. While this location offers some environmental protection (rain, debris, etc), space for mounting, and minimizes stray inductance for the $\mathrm{PE}$, the ambient temperatures can exceed $105^{\circ} \mathrm{C}$ because of the nearby internal combustion engine (ICE). Unfortunately, PE are highly temperature dependent, and $\mathrm{PE}$ junction temperatures above $105^{\circ} \mathrm{C}$ greatly reduce their reliability and performance. Therefore, PE must meet strict automobile manufacturers' design criteria when used in HEVs. The four most import design criteria for the automotive industry are weight, size, reliability, and cost [1].

The thermal management system for power electronic devices plays an important role for all four criteria. Typical thermal management systems occupy one-third of the total volume for a power converter and in many cases weigh more than the converter itself [2]. Presently, HEVs use a liquidcooled heat sink where ethylene glycol is circulated separately from the ICE. This system provides minimally adequate cooling at $105^{\circ} \mathrm{C}$ (FreedomCAR Program specifications) [1]. Another disadvantage in using a separate coolant loop is an increase in vehicle weight because of the additional components of the separate loop such as coolant, coolant hoses, a pump, and a radiator.

However, with slight modification to existing air-conditioner $(\mathrm{A} / \mathrm{C})$ systems in automobiles, they can be used to cool PE devices. Nearly all new automobiles sold in the United States are equipped with an A/C system using R134a refrigerant for cooling the vehicle's interior for passenger comfort. Utilization of the existing $\mathrm{A} / \mathrm{C}$ system for cooling the cabin and PE is presented in this paper as a means to help meet the design criteria described previously.

\section{ENERGy DisSipation OF Silicon DeVICES}

Silicon (Si) based power electronics devices dissipate heat energy during the turn-on, turn-off, and conduction periods shown in Fig. 1. Energy dissipation (loss) in semiconductors increases as the junction temperature increases, and this can cause catastrophic failure if the thermal energy is not managed within specification. Typically, the junction temperature of $\mathrm{Si}$ power devices is limited to $150^{\circ} \mathrm{C}$, and it is directly proportional to reliability. As a rule of thumb, the failure rate for semiconductor devices doubles for each $10-15^{\circ} \mathrm{C}$ temperature rise above $50^{\circ} \mathrm{C}[3]$.

Total average power dissipation in semiconductors during switching can be calculated by (1):

$$
P_{t}=\frac{1}{T_{s}} \int_{0}^{T_{s}} v(t) \cdot i(t) d t
$$




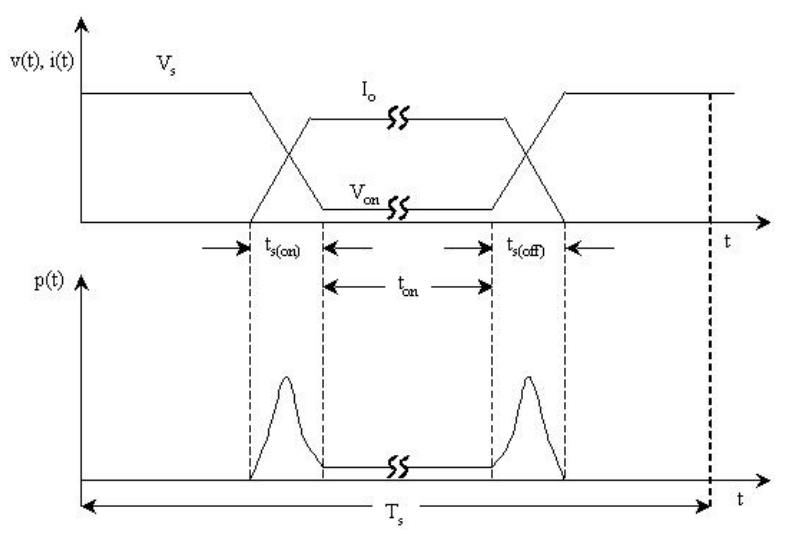

Fig. 1. Controllable semiconductor switching characteristics [3].

where $T_{s}$ denotes the period of one complete cycle, $v(t)$ is the voltage across the collector-emitter, and $i(t)$ is the current through the collector. The equation consists of power dissipated during turn-on, turn-off, conduction, and blocking.

\section{REFRIGERATION PROPERTIES}

Cooling by nucleate boiling is one of most efficient means of removing heat from a component [4-8]. The refrigerant is in a saturated state and is in direct contact with the PE exterior surfaces. Until now, R134a was not intended to cool electrical equipment. It was designed for automobile passenger climate control; however, R134a has exceptional thermal characteristics that are useful in cooling semiconductors. R134a has a low boiling point, low vapor expansion, high energy transfer capability, and medium operating pressures. A comparison of R134a, FC-72 (Fluorinert), and water are shown in Table 1. Water has nearly ideal thermal conductivity, but in the vapor state, the volume is 19,000 times larger than in the liquid state. Also, water is corrosive and a poor dielectric. On the other hand, FC-72 is designed to cool electronics; therefore, it is designed with excellent dielectric properties. However, FC-72 has a moderate ability to absorb heat, high expansion rate from liquid to vapor, and requires a large amount of energy to circulate. R134a is considered a nearly ideal refrigerant for cooling power electronics such as those found in HEVs.

TABLE I

COMPARISON OF REFRIGERANT CHARACTERISTICS

\begin{tabular}{|c|c|c|c|c|c|}
\cline { 2 - 6 } & $\begin{array}{c}\text { Latent } \\
\text { Heat } \\
{[\mathrm{kJ} / \mathrm{kg}]}\end{array}$ & $\begin{array}{c}\text { Specific } \\
\text { Volum e } \\
\text { at } 40^{\circ} \mathrm{C} \\
{[\ell / \mathrm{kg}]}\end{array}$ & $\begin{array}{c}\text { Vapor } \\
\text { Flow rate } \\
\text { per kW } \\
{[\ell / \mathrm{s}]}\end{array}$ & $\begin{array}{c}\text { Vapor } \\
\text { Energy } \\
\text { Capability } \\
{[\mathrm{kJ} / \ell]}\end{array}$ & $\begin{array}{c}\text { Boiling } \\
\text { Point } \\
{\left[{ }^{\circ} \mathrm{C}\right]}\end{array}$ \\
\hline R134a & 217 & 20 & 0.1 & 11 & -26.6 \\
\hline FC-72 & 89 & 147 & 1.7 & 0.6 & 57 \\
\hline Water & 2320 & 19000 & 8.2 & 0.1 & 100 \\
\hline
\end{tabular}

\section{EXPERIMENTAL SETUP}

The experimental two-phase cooling system is shown in Figs. 2(a) and 2(b). The experimental components are comprised of a glass vessel with aluminum top and bottom flanges that enclose the refrigerant, IGBT, gate-controller card, and associated snubber components. The electrical connections for the dc-bus and gate-controller card are feedthrough pins that are held in place using potted epoxy for a leak-proof seal. The IGBT is an International Rectifier IRGBC20UD2 configured in a simple chopper circuit with a pure resistive load as shown in Fig. 3. The IGBT was cycled on and off at $1 \mathrm{kHz}$ with a $50 \%$ duty cycle and a gate voltage of $13.0 \mathrm{~V}$. The voltage $V_{d c}$ applied was $480 \mathrm{~V}$ and a fixed load resistance $R_{L}$ of $140 \Omega$ drew an average current of $6 \mathrm{~A}$.

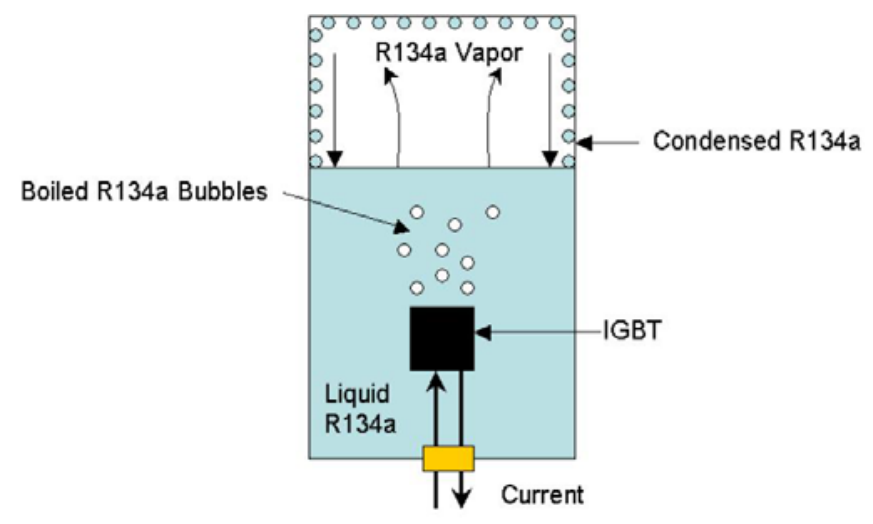

(a) Submerged R134a cooled technique

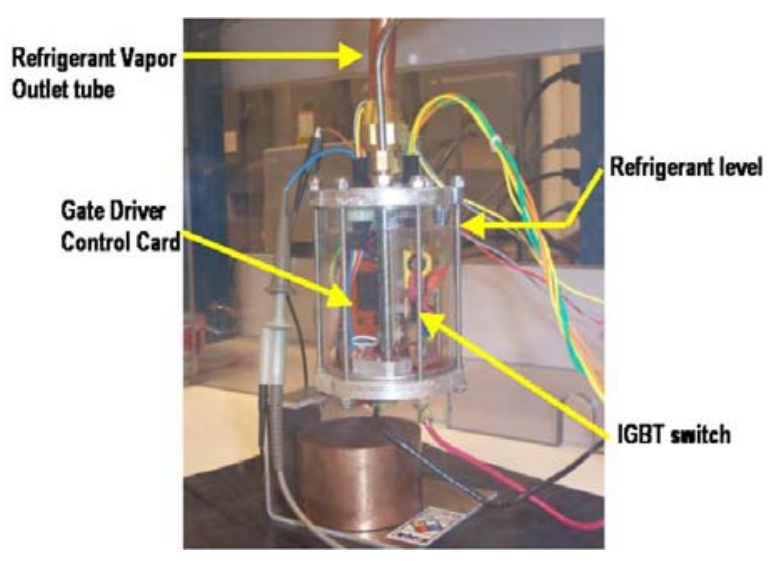

(b) Test vessel including power electronics devices

Fig. 2. Experimental refrigerant system.

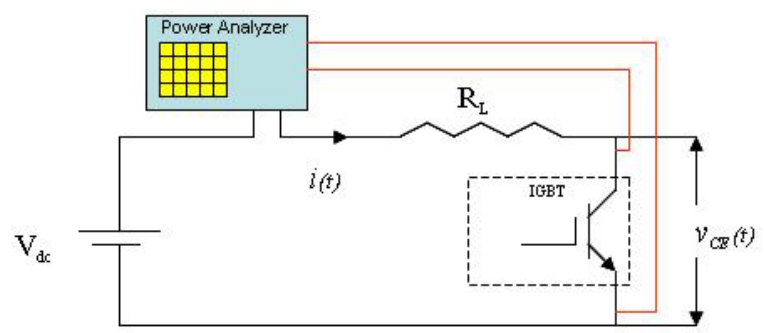

Fig. 3. Experimental circuit. 


\section{Dielectric Test Results}

The same experimental circuit was tested in both air-cooled and R134a bath environments to investigate whether R134a has high dielectric characteristics and non-deterioration effects on electronic components. Figs. 4(a) and 4(b) are views of voltage and current transitions during one switching period. The voltage and current waveforms are identical in both the air-cooled and R134a-cooled cases. Fig. 4(c) is an expanded view of the voltage and current turn-off transitions. This indicates R134a does not change the IGBT turn-on and turn-off transition by introducing additional capacitance across the IGBT terminals or the gate-controller card. Fig. 4(d) is a graph of instantaneous and average power for both tests. The average power loss for the R134a-cooled test was $24.73 \mathrm{~W}$ using (1) while the air-cooled test was $22.21 \mathrm{~W}$. These electrical components have been submerged in the refrigerant for over 300 days during which the test was repeated regularly with no evidence of damage. For this specific configuration, $\mathrm{R} 134 \mathrm{a}$ was determined to have a heat flux of $114 \mathrm{~W} / \mathrm{cm}^{2}$.

The power loss for each IGBT state of operation (conduction, blocking, turn-on, and turn-off) is shown in Table II. Conduction loss is the largest power loss while the IGBT is operating within rated switching frequency $(1 \mathrm{kHz}$ for this experiment).
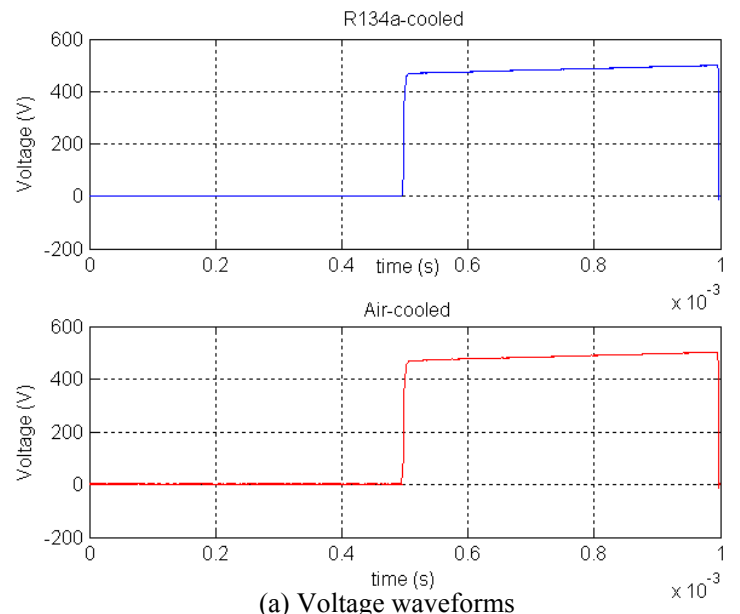

(a) Voltage waveforms
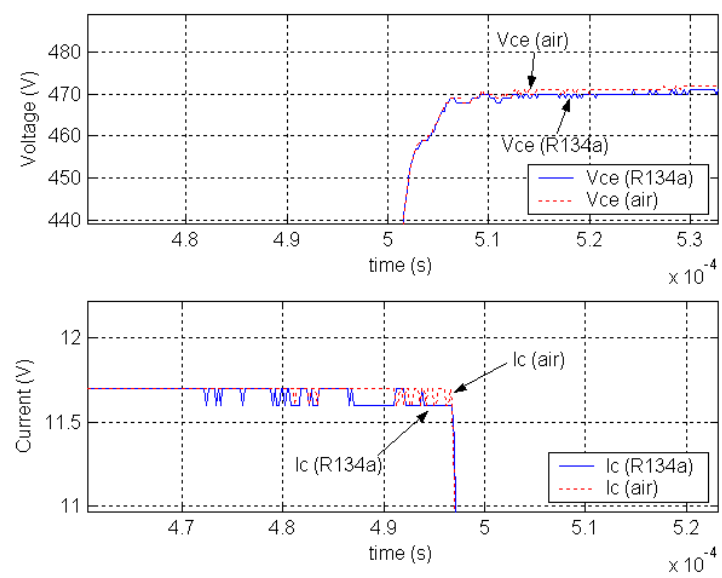

(c) Expanded voltage and current device turn-off
TABLE II

POWER DISSIPATED FROM TESTED IGBT AND PWL COMPARISON.

\begin{tabular}{|c|c|c|c|c|c|}
\hline & $\begin{array}{c}\mathbf{P}_{\text {total }} \\
(\mathbf{W})\end{array}$ & $\begin{array}{c}\mathbf{P}_{\text {blocking }} \\
(\mathbf{W})\end{array}$ & $\begin{array}{c}\mathbf{P}_{\text {s(on) }} \\
(\mathbf{W})\end{array}$ & $\begin{array}{c}\mathbf{P}_{\text {s(off) }} \\
(\mathbf{W})\end{array}$ & $\begin{array}{c}\mathbf{P}_{\text {cond }} \\
(\mathbf{W})\end{array}$ \\
\hline Air & 22.12 & 2.65 & 0.38 & 5.85 & 13.24 \\
\hline R134a & 24.73 & 2.26 & 0.41 & 5.75 & 16.32 \\
\hline
\end{tabular}

\section{Mock Automotive R134a A/C Results}

The results from the air-cooled and R134a-cooled experiments demonstrated that the R134a provides no interference with normal operation of the power circuit. Switching characteristics of the IGBT were not affected; therefore, to take full advantage of the thermal characteristics of R134a, the circuit is operated simultaneously with the mock automotive A/C system shown in Fig. 5. The mock automotive $\mathrm{A} / \mathrm{C}$ system is constructed from components that comprise a 2003 Buick Park Avenue A/C system, which includes a compressor, condenser, evaporator, and control system. Two service ports are placed in parallel with the evaporator refrigeration circuit to provide external mounting and operation
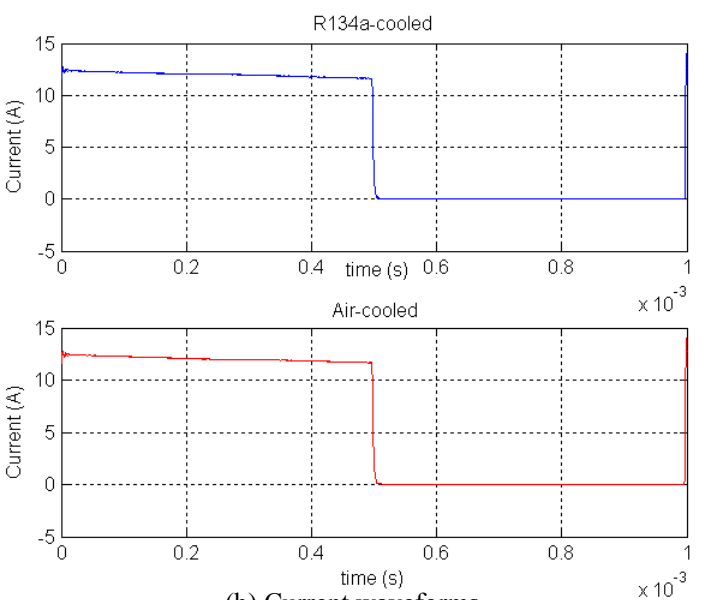

(b) Current waveforms
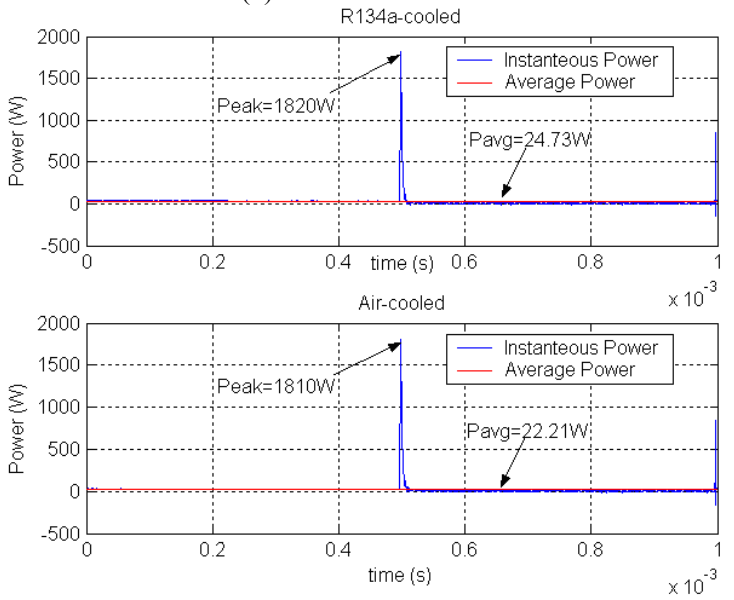

(d) Instantaneous and average power loss

Fig. 4. Experimental results for R134a-cooled and air-cooled power systems. 


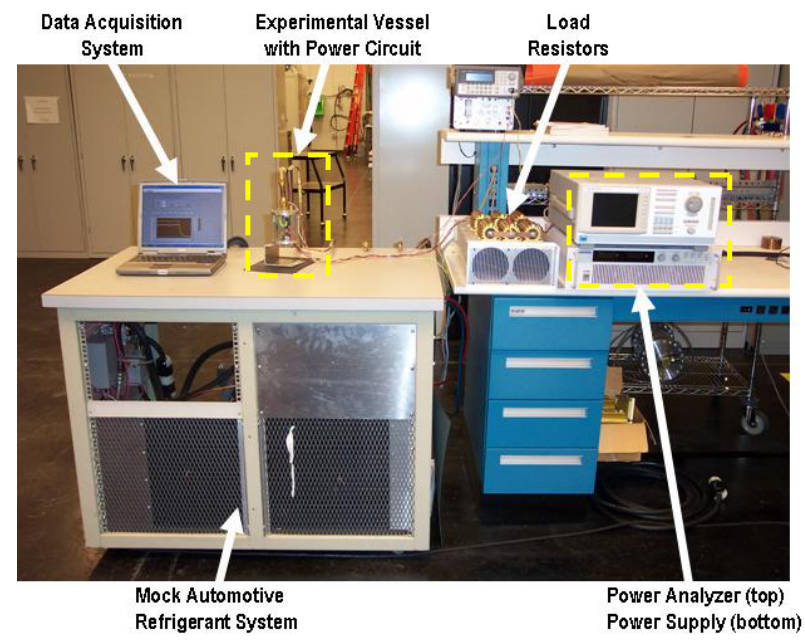

Fig. 5. Mock automotive R134a A/C system including experiment

for the test vessel. The automotive A/C system has $9320 \mathrm{~W}$ of cooling capacity for cooling the cabin, as well as to provide ample capacity for cooling the IGBT [10].

The objective of this experiment is to observe the IGBT case and vessel refrigerant temperatures, IGBT voltage and current
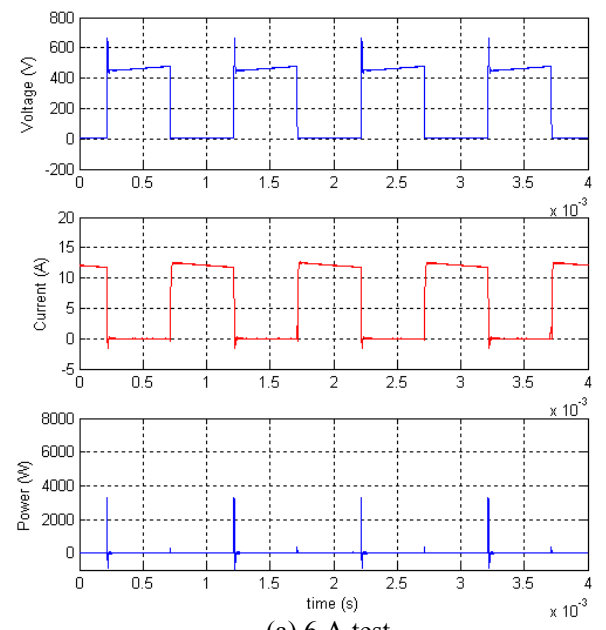

(a) $6 \mathrm{~A}$ test
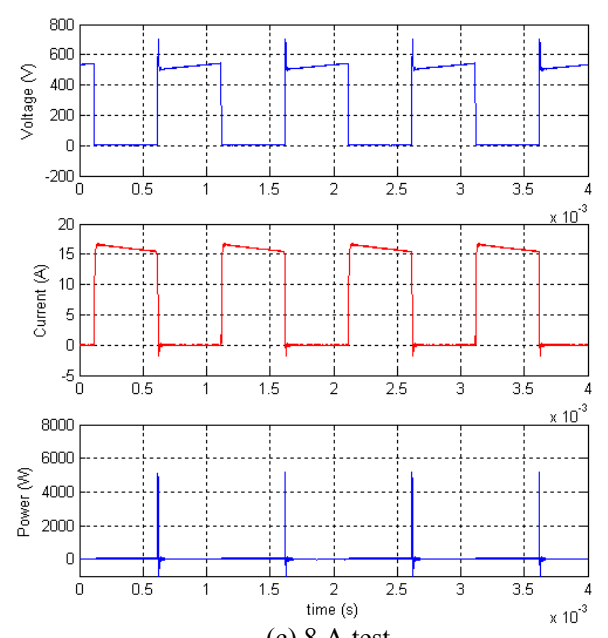

(c) $8 \mathrm{~A}$ test waveforms, and $\mathrm{A} / \mathrm{C}$ system behavior during an increase in forward current. The forward current is increased by $1 \mathrm{~A}$ increments at 30 minute intervals beginning with $6 \mathrm{~A}$.

The test results from the mock A/C test are shown in Figs. 6 and 7. Fig. 6 is a plot of the ambient, IGBT case, and vessel

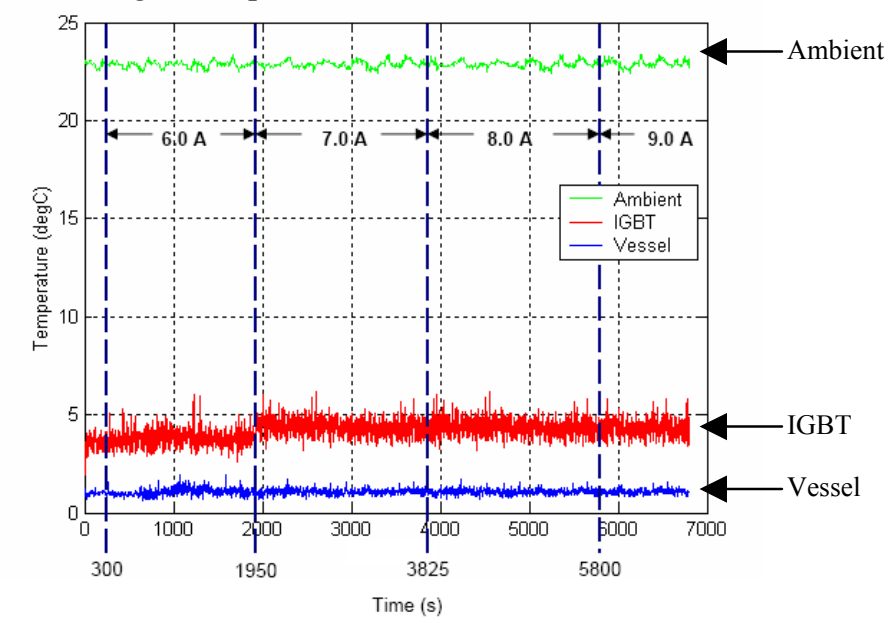

Fig. 6. Experimental temperature versus time.
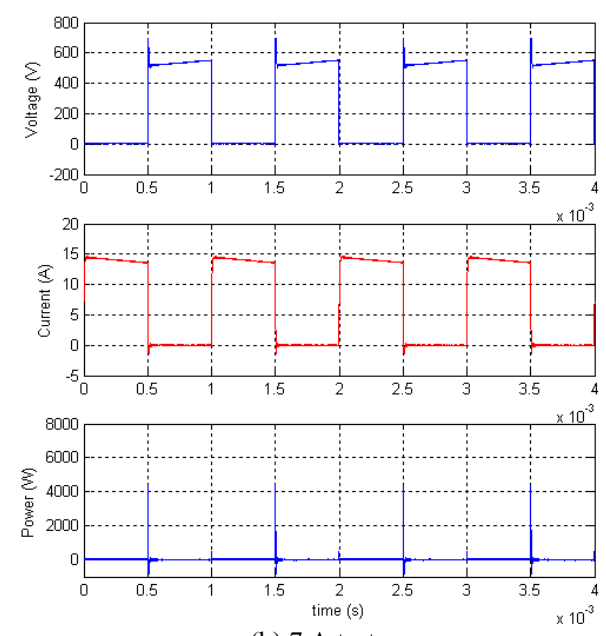

(b) 7 A test
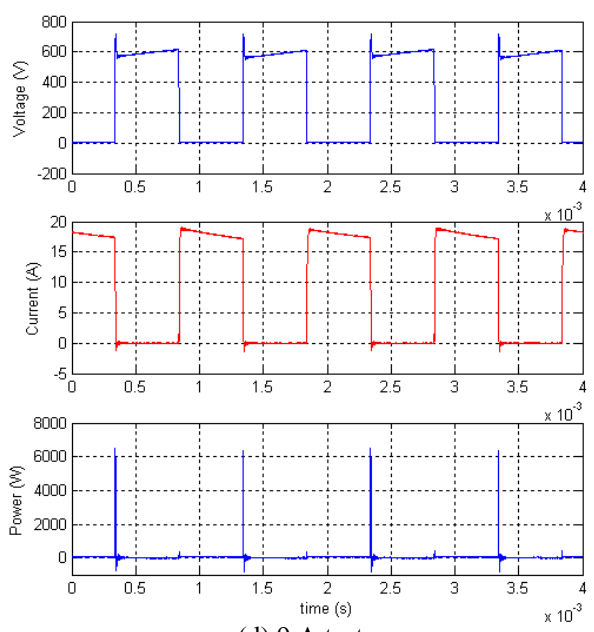

(d) 9 A test

Fig. 7. Experimental voltage, current, and power waveforms from automotive air conditioner system cooling an IGBT. 
refrigerant temperatures versus time. The IGBT case, vessel refrigerant, and ambient temperatures remain nearly constant throughout the average forward current levels of $6,7,8$, and 9 A. The IGBT case temperature was calculated to be $4.2^{\circ} \mathrm{C}$, while the vessel refrigerant was on average $1.1^{\circ} \mathrm{C}$, and the ambient temperature was $22.9^{\circ} \mathrm{C}$ external to the test vessel. The IGBT failed at the beginning of the $10 \mathrm{~A}$ interval, at which point the IGBT was operating beyond its rating by conducting a peak current of 20 A for approximately $0.5 \mathrm{~ms}$.

Fig. 7(a)-(d) are plots of the instantaneous IGBT voltage $v_{c e}(t)$, current $i_{c}(t)$, and power $p(t)$ for the average current levels of $6,7,8$, and $9 \mathrm{~A}$. Conclusions from the data in this test indicate the automotive $\mathrm{A} / \mathrm{C}$ system has more than sufficient cooling capacity to cool the single test IGBT. The temperature of the IGBT case remained well below ambient temperature, thus it can be concluded that the $\mathrm{A} / \mathrm{C}$ system can dissipate more heat from multiple PE devices.

\section{THREE-PHASE INVERTER}

One requirement of the FreedomCAR Program is that the electric propulsion system, including the inverter as shown in Fig. 8, must be capable of delivering $30 \mathrm{~kW}$ of continuous power [1]. The efficiency of the inverter is an important factor because it is an indicator of wasted power converted into heat by the PE devices. The wasted power robs the power from the motor and draws extra power from the batteries. Efficiency for an inverter is based on many variables such as semiconductor ratings, switching frequency, supply voltage, phase current, stray inductance, etc. Typically, an inverter's efficiency is $96 \%$; therefore, an estimated loss for a $30 \mathrm{~kW}$ inverter is 1200 $\mathrm{W}$ continuous.

The inverter was simulated using six thin-film resistors as the PE devices shown in Fig. 9. Resistors were used to emulate heat from an inverter because the power loss in an inverter is considered purely resistive, thus an $I^{2} R$ loss can model the average power loss of each IGBT during switching. The resistors were submerged and cooled by the mock automotive $\mathrm{A} / \mathrm{C}$ system.

The test procedure was to supply the resistors with a dc voltage from which the resistors draw $16 \mathrm{~A}$ of current. The current was increased by 1 A every 30 minutes of operation.

Each branch temperature represented the case temperature of the IGBT device in that branch. A plot of the resistor temperatures of each branch versus time is shown in Fig. 10. At first look, the resistor temperatures are different because of the configuration of the resistors (see Fig. 9 (b)). The center resistor branch receives heat energy from the two neighboring resistor branches conducted by the metal substrate to which the resistors are mounted, thus increasing the center branch resistor

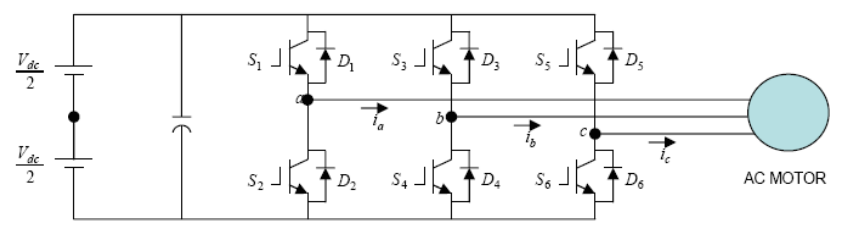

Fig. 8. Three-phase inverter driving an ac machine.

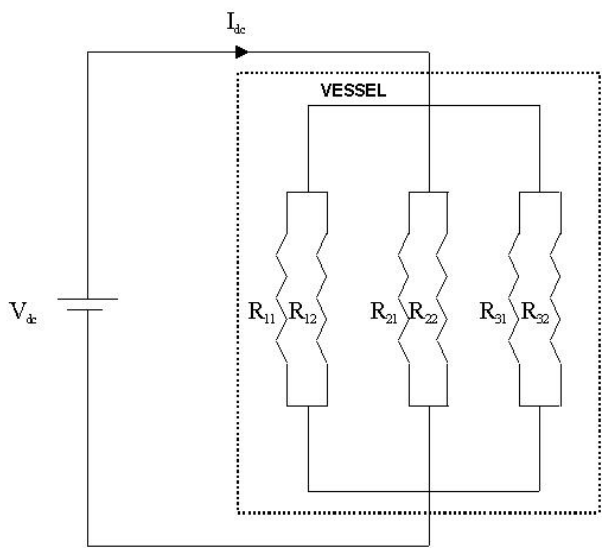

(a) Circuit diagram

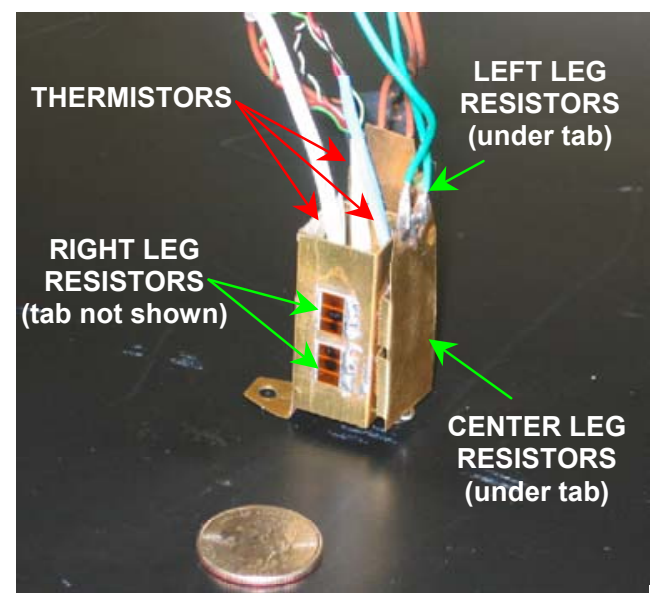

(b) Resistor Assembly

Fig. 9. Thin-film resistor circuit.

temperature. The left branch is the coolest because it is placed nearest to the inlet refrigerant tube, where a fresh supply of refrigerant is being forced across the branch.

Initially the resistors dissipate $422 \mathrm{~W}$ at $16 \mathrm{~A}$ as illustrated in Table III, which shows each interval of power dissipation. During this period, temperature fluctuations are present due to adjustments of the bulk refrigerant level within the vessel.

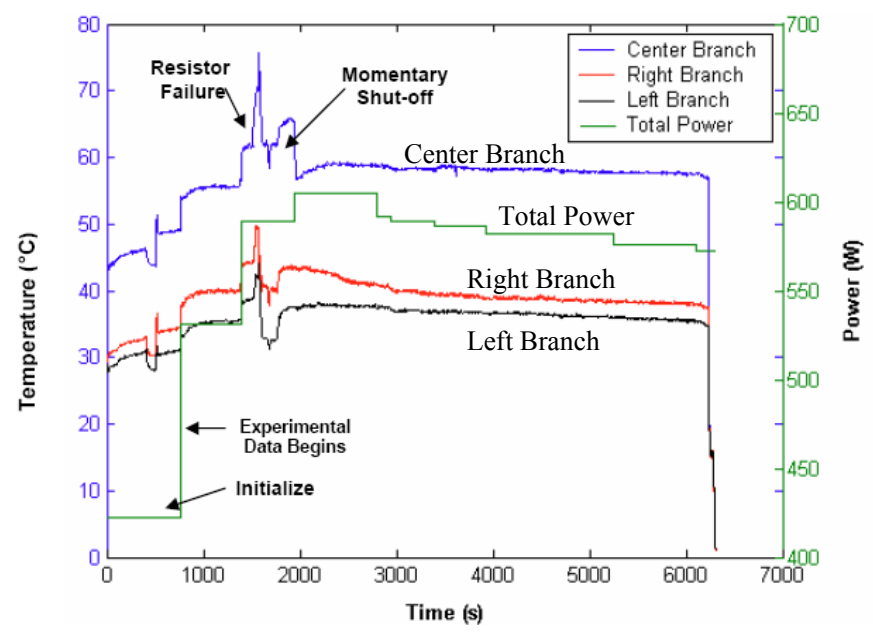

Fig. 9. Resistor temperature and power dissipation versus time. 
TABLE III

THIN-FILM RESISTOR EXPERIMENTAL RESULTS

\begin{tabular}{|c|c|c|c|c|}
\cline { 3 - 5 } \multicolumn{2}{c|}{} & \multicolumn{3}{|c|}{ Branch Temperature $\left({ }^{\circ} \mathbf{C}\right)$} \\
\hline $\boldsymbol{I}_{\text {avg }}(\mathbf{A})$ & $\boldsymbol{P}_{\text {total }}(\mathbf{W})$ & Center & Right & Left \\
\hline 16.0 & 422 & 55.5 & 39.7 & 35.4 \\
\hline 18.0 & 531 & 56.6 & 40.9 & 36.0 \\
\hline 19.0 & 589 & 61.8 & 43.9 & 38.5 \\
\hline 18.4 & 605 & 58.9 & 41.0 & 37.7 \\
\hline 18.0 & 592 & 58.8 & 40.8 & 37.5 \\
\hline 17.9 & 589 & 58.3 & 38.7 & 36.9 \\
\hline 17.8 & 586 & 58.3 & 39.2 & 36.8 \\
\hline 17.7 & 582 & 58.1 & 38.7 & 36.5 \\
\hline 17.5 & 576 & 57.5 & 37.8 & 35.5 \\
\hline 17.4 & 572 & 57.5 & 37.7 & 35.4 \\
\hline
\end{tabular}

Once the liquid level settled, the current was increased to $18 \mathrm{~A}$, and the total power dissipated was $531 \mathrm{~W}$. The center, right, and left branch temperatures reached steady state temperatures of $56.6^{\circ} \mathrm{C}, 40.9^{\circ} \mathrm{C}$, and $36.0^{\circ} \mathrm{C}$, respectively. The current level was then set to $19 \mathrm{~A}$, and the total power dissipated was $589 \mathrm{~W}$. After 100 seconds, a portion of the center branch resistor failed at a temperature of $61.8^{\circ} \mathrm{C}$. The center, right, and left branch temperatures reached a peak of $75.6^{\circ} \mathrm{C}, 49.7^{\circ} \mathrm{C}$, and $44.0^{\circ} \mathrm{C}$ respectively; at which point, the power supply was deactivated for 80 seconds. A decision was made to continue the experiment, and the power supply was again activated.

The results of the experiment demonstrate that the automotive $\mathrm{A} / \mathrm{C}$ is capable of cooling the resistors up to 605 $\mathrm{W}$. The power ratings of the resistors are unknown, although a reasonable conclusion based upon a quadratic extrapolation of the experimental temperature versus forward current results is that if the resistors have a larger current rating, the automotive $\mathrm{A} / \mathrm{C}$ could sustain the resistor temperatures below $125^{\circ} \mathrm{C}$ at power levels up to $1200 \mathrm{~W}$ as shown in Table IV.

TABLE IV

EXTRAPOLATED THIN-FILM RESISTOR RESULTS

\begin{tabular}{|c|c|c|c|c|c|}
\cline { 3 - 6 } \multicolumn{2}{c|}{} & \multicolumn{5}{c|}{ Branch Temperature $\left({ }^{\circ} \mathbf{C}\right)$} \\
\hline $\boldsymbol{I}_{\text {avg }}(\mathbf{A})$ & $\boldsymbol{P}_{\text {total }}(\mathbf{W})$ & Center & Right & Left & Bulk \\
\hline 0.0 & 0 & 0.0 & 0.0 & 0.0 & 0.0 \\
\hline 10.0 & 165 & 17.8 & 13.1 & 14.5 & 10.0 \\
\hline 20.0 & 659 & 61.5 & 43.9 & 38.4 & 26.3 \\
\hline 27.0 & 1201 & 107.1 & 75.5 & 60.0 & 40.8 \\
\hline 30.0 & 1483 & 130.5 & 91.6 & 70.5 & 47.9 \\
\hline 34.0 & 1905 & 165.2 & 115.6 & 85.6 & 58.0 \\
\hline
\end{tabular}

\section{ACTIVE IGBT JUNCTION COOLING}

Experimental results in sections VI and VII demonstrate that the removal of heat energy away from the generating area is a major limiting factor for large forward current capabilities in PE devices. As an example, the tested IGBT junction to case thermal resistance (a material's ability to conduct heat energy) is $2.1 \Omega$, which translates into a significant difference in temperature between the case and the junction. Presented in this section, the case is theoretically removed from the junction, and a simulation is performed at which the IGBT junction is actively cooled by an automotive R134a A/C system.

Theoretically separating the case from the junction will expose the junction layer to the ambient. Knowing that exposing the junction to the ambient will potentially pollute the Si die, a possible special coating should be applied to shield the Si from contaminates. The special coating is estimated to be a few thousandths of an inch applied to the surfaces of the junction layer, and it should have a thermal resistance of $0.5 \Omega$, similar to thermal grease, which is applied between a PE device and a heat sink to provide even thermal conductivity.

The junction layer temperature, $T_{j}$, of a single exposed junction IGBT is simulated and compared to a cased IGBT. The IGBTs are operating under identical switching frequency, duty cycle, and refrigerant temperature. The simulation incorporates the steady state thermal circuit model of the IGBT and cooling system described in Fig. 11 and (2), where simple Ohm's Law equations can be used. Based on the thermal circuit, (2) solves for the temperature of the junction $T_{j}$, where the thermal resistances of the junction-to-case, case-to-sink, sink-to-ambient, ambient temperature, and the total power dissipated $\left(R_{\theta j c}, R_{\theta c s}, R_{\theta s a}, T_{a}\right.$ and $P_{\text {total }}$ respectively) are given, then:

$$
T_{j}=P_{\text {total }}\left(R_{\theta j c}+R_{\theta c s}+R_{\theta s a}\right)+T_{a}
$$

The values for $P_{\text {total }}, R_{\theta c s}, R_{\theta s a}$, and $T_{a}$ are taken from the experimental results in section VI. The case to R134a resistance, $R_{\theta c a}=R_{\theta c s}+R_{\theta s a}$, was determined from the IGBT case temperature, $T_{c}$, of $3.0^{\circ} \mathrm{C}$, refrigerant temperature, $T_{a}$, of $1.5^{\circ} \mathrm{C}$,

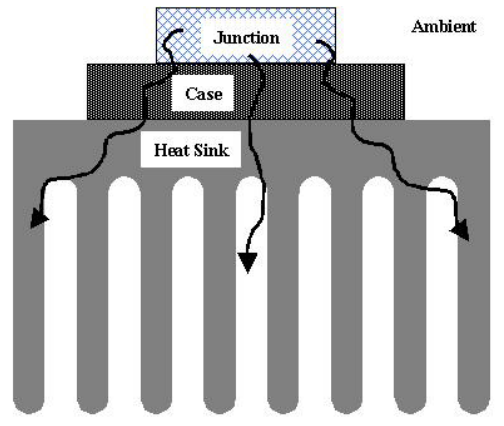

(a) Heat energy flow in PE devices

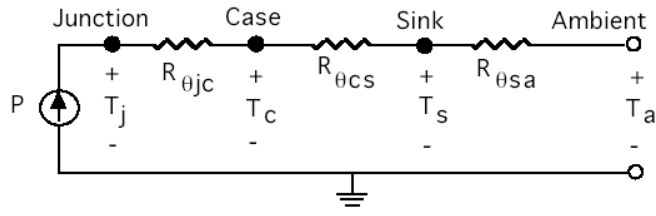

(b) Steady-state thermal circuit

Fig. 11. Semiconductor thermal model. 
and the total average power dissipated by the IGBT of $25.5 \mathrm{~W}$,

therefore, $R_{\theta c a}=\frac{T_{c}-T_{a}}{P_{\text {total }}}=0.0588 \Omega$.

The simulation results are shown in Fig. 12, where as the forward current increases, the junction temperature increases for both IGBTs. The manufacturer determined the allowable maximum temperature to be $125^{\circ} \mathrm{C}$. The IGBT with the attached case experiences a maximum junction temperature at 8.5 A; however, the exposed junction IGBT reaches $17.5 \mathrm{~A}$ before meeting the maximum junction temperature. At $17.5 \mathrm{~A}$, the junction temperature of the IGBT with a case was estimated to be $423^{\circ} \mathrm{C}$ by simulation, which is unachievable in a practical $\mathrm{Si}$ semiconductor.

HEVs would be an ideal application for an inverter built from exposed junction IGBTs because the inverter would be smaller, lighter, and more reliable than present designs that have a bulky case. The IGBTs would have a greater current capability; therefore, they will not have to be overrated.

\section{CONCLUSIONS}

PEs are vital to the operation and performance of HEVs because they provide the interface between the energy sources and the traction drive motor. As with any practical system, PE devices have losses in the form of heat energy during normal switching operation, which has the ability to damage or destroy the device. Thus, to maintain reliability of the PE system, the heat energy produced must be removed. Present HEV cooling methods provide adequate cooling effects, but lack sufficient junction temperature control to maintain long-term reliability.

The technique described in this paper incorporates R134a refrigerant and the on board $\mathrm{A} / \mathrm{C}$ system to keep PE devices in a reliable range of temperatures. Proven by experimentation, $\mathrm{R} 134 \mathrm{a}$ has no damaging effects on the normal operation for 300 days on a submerged IGBT, gate controller card, and snubber circuits. The IGBT circuit was operated in an air-

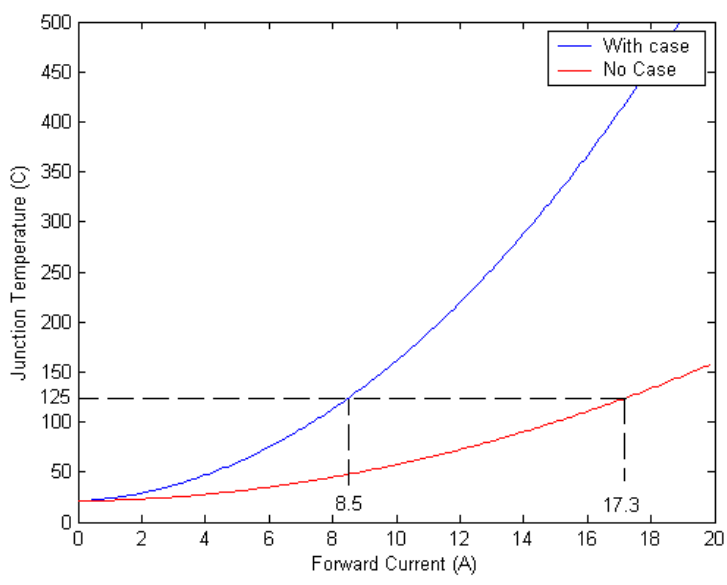

Fig. 12. IGBT Junction temperature versus forward current cooled and R134a environments where the voltage and current waveforms were compared. Results indicate R134a induces no additional delay or switching losses on the IGBT circuit. The automotive $\mathrm{A} / \mathrm{C}$ system provided a constant case temperature of $4.2^{\circ} \mathrm{C}$.

The automotive A/C system was shown to have more than adequate cooling capacity to cool a six-IGBT $30 \mathrm{~kW}$ inverter with $96 \%$ efficiency. Based on FreedomCAR specifications, normal operation of the inverter IGBTs will dissipate $1200 \mathrm{~W}$ of heat energy. The thin-film resistor experiment proved that the automotive $\mathrm{A} / \mathrm{C}$ could keep the junction temperature below $62^{\circ} \mathrm{C}$ while dissipating $600 \mathrm{~W}$. After extrapolating the results, the $\mathrm{A} / \mathrm{C}$ system is expected to be able to dissipate $1200 \mathrm{~W}$ of heat energy and keep the junction temperature below the $125^{\circ} \mathrm{C}$ target.

In addition, experimental data proved that the thermal resistance of the case limits a PE device's ability to remove heat energy from the junction layer. A simulated comparison of an IGBT with a case attached and an exposed junction IGBT was performed that incorporated experimental results. The results from the simulation indicate the exposed junction IGBT technique would benefit by reducing the junction temperature, increasing forward current ratings, and increasing reliability of the device.

\section{REFERENCES}

[1] http://www.eere.energy.gov, "Advanced Power Electronics and Electronic Machines,” June 2004.

[2] M. Behnia, "Cooling Problems and Thermal Issues in High Power Electronics- A Multi Faceted Design Approach," $5^{\text {th }}$ Int. Conf. On Thermal and Mechanical Simulation and Experiments in Microelectronics and Micro-systems, 10-12 May 2004, pp. 519-526.

[3] N. Mohan, T. M. Underland, W. P. Robbins, Power Electronics, Converters, Applications, and Design, $3^{\text {rd }}$ ed., John Wiley \& Sons, Inc, 2003, pp. 730-742.

[4] T. Jomard, U. Eckes, E. Touvier, M. Lallemand, "Modeling of the TwoPhase Cooling of a Power Semiconductor and Its Associated Evaporators," Semiconductor Thermal Measurement and Management Symposium, 3-5 Feb. 1992, pp. 20-24.

[5] P. H. Desai, G. Wiegner, "Evaluation of Freon Modules for Power Electronics Design for a Locomotive Traction Drive," IEEE Transactions on Industry Applications, vol. 26, no. 3, May/June 1990, pp. 394-400.

[6] H. Kristiansen, T. Fallet, A. Bjorneklett, "A Study of the Evaporation Heat Transfer in the Cooling of High Power Electronics," Proceedings of IEEE Semiconductor Thermal Measurement and Management Symposium, 1-3 Feb. 1994, pp. 114-120.

[7] I. Mudawar, "Direct-Immersion Cooling for High Power Electronic Chips," InterSociety Conference on Thermal Phenomena in Electronics Systems, 5-8 Feb. 1992, pp. 74-84.

[8] G. N. Dulnev, V. A. Korablyev, A. V. Sharkov, "Evaporation Cooling of High Power Electronic Devices," IEEE Transactions on Components, Packaging, and Manufacturing Technology, vol. 19, no. 3, Sept. 1996, pp. 431-434.

[9] D. Faulkner, M. Khotan, R. Shekarriz, "Practical Design of a $1000 \mathrm{~W} / \mathrm{cm}^{2}$ Cooling System," Semiconductor Thermal Measurement and Management Symposium, 11-13 March 2003, pp. 223-230.

[10] G. Major, General Motors, 28 Sept. 2004, personal correspondence. 